\title{
BMJ Open Adverse childhood or adult experiences and risk of bilateral oophorectomy: a population-based case-control study
}

\author{
Liliana Gazzuola Rocca, ${ }^{1}$ Carin Y Smith, ${ }^{2}$ Brandon R Grossardt, ${ }^{2}$ \\ Stephanie S Faubion, ${ }^{3,4}$ Lynne T Shuster, ${ }^{4}$ Elizabeth A Stewart, ${ }^{3,5,6}$ \\ Walter A Rocca ${ }^{1,7}$
}

To cite: Gazzuola Rocca L, Smith CY, Grossardt BR, et al. Adverse childhood or adult experiences and risk of bilateral oophorectomy: a population-based casecontrol study. BMJ Open 2017;7:e016045. doi:10.1136/ bmjopen-2017-016045

- Prepublication history and additional material are available. To view these files, please visit the journal online (http://dx.doi.org/ 10.1136/ bmjopen-2017-016045)

Received 23 January 2017 Revised 28 February 2017 Accepted 6 April 2017

CrossMark

For numbered affiliations see end of article.

Correspondence to DrWalter A Rocca; rocca@ mayo.edu

\section{ABSTRACT}

Objectives Bilateral oophorectomy has commonly been performed in conjunction with hysterectomy even in women without a clear ovarian indication; however, oophorectomy may have long-term deleterious consequences. To better understand this surgical practice from the woman's perspective, we studied the possible association of adverse childhood or adult experiences with the subsequent occurrence of bilateral oophorectomy. Design Population-based case-control study. Setting Olmsted County, Minnesota (USA). Participants From an established population-based cohort study, we sampled 128 women who underwent bilateral oophorectomy before age 46 years for a noncancerous condition in 1988-2007 (cases) and 128 agematched controls ( \pm 1 year).

Methods Information about adverse experiences was abstracted from the medical records dating back to age 15 years or earlier archived in the Rochester Epidemiology Project (REP) records-linkage system. Adverse childhood experiences were summarised using the Adverse Childhood Experience (ACE) score.

Results We observed an association of bilateral oophorectomy performed before age 46 years with verbal or emotional abuse, physical abuse, any abuse, substance abuse in the household, and with an ACE score $\geq 1$ experienced before age 19 years $(\mathrm{OR}=3.23 ; 95 \% \mathrm{Cl}$ 1.73 to $6.02 ; p<0.001)$. In women who underwent the oophorectomy before age 40 years, we also observed a strong association with physical abuse experienced during adulthood ( $\mathrm{OR}=4.33 ; 95 \% \mathrm{Cl} 1.23$ to $15.21 ; \mathrm{p}=0.02$ ). Several of the associations were higher in women who underwent oophorectomy at a younger age $(<40$ years) and in women without an ovarian indication for the surgery. None of the psychosocial or medical variables explored as potential confounders or intervening variables changed the results noticeably.

Conclusions Women who suffered adverse childhood experiences or adult abuse are at increased risk of undergoing bilateral oophorectomy before menopause. We suggest that the association may be explained by a series of biological, emotional, and psychodynamic mechanisms.

\section{INTRODUCTION}

The increased morbidity and mortality associated with bilateral oophorectomy have

\section{Strengths and limitations of this study}

- To our knowledge, this is the first study to show an association between adverse childhood and adult experiences and bilateral oophorectomy.

- The records-linkage system of the Rochester Epidemiology Project provided a unique research infrastructure to test these life course associations using data collected historically over approximately 40 years.

- The participation of women in the study was high because of the passive nature of the records-linkage system.

- The study may have underestimated the frequency of adverse childhood or adult experiences, and the statistical power was limited for some stratified analyses.

- In analyses using the Adverse Childhood Experiences score, all adverse events were assumed to have the same weight. In addition, we did not consider the overall family environment or the presence of surrogate caring figures.

been established in a number of studies, especially when oophorectomy occurs at a younger age. ${ }^{1-7}$ Many bilateral oophorectomies, up to half in some series, are performed in conjunction with a hysterectomy without a specified ovarian indication for oophorectomy. ${ }^{4}$ This practice reflects the unresolved controversy about the advantages and disadvantages of bilateral oophorectomy performed as a preventive measure against ovarian cancer. ${ }^{8-14}$ Intraoperative events, surgeons' preferences, and women's feelings and past experiences may all play a role in this process. This study of women's experiences associated with oophorectomy was prompted by two observations.

First, during the abstraction of medical records for a cohort study of the association between bilateral oophorectomy and the risk of developing multimorbidity, ${ }^{4}$ we noted 
that a majority of women presented to their physicians with gynaecological symptoms that did not correspond to a major identifiable pathology and requested a hysterectomy to reduce their symptoms. When the physician suggested that a concurrent bilateral oophorectomy would reduce the risk of ovarian cancer and the need for future gynaecological surgeries, the women consented to concomitant oophorectomy. Second, we noted that some of these women reported as part of a psychiatric evaluation a history of adverse childhood experiences or abuse during adult life. These women also expressed the belief that their sexual and reproductive life had been a source of continuous distress. However, for many women, this pertinent history was not discussed during the evaluation for the gynaecological symptoms that led to the hysterectomy and oophorectomy.

We thus tested the hypothesis that adverse experiences of abuse, violence, or neglect experienced during childhood or experiences of abuse during adulthood are associated with the propensity of women to undergo bilateral oophorectomy, almost always in conjunction with hysterectomy, before the typical age of natural menopause. To test this hypothesis, we constructed a case-control study within an existing cohort study described elsewhere. ${ }^{4}$

\section{METHODS}

\section{Cases and controls}

Our cases and controls were derived from a cohort study designed to evaluate the long-term health outcomes of oophorectomy, as described elsewhere. ${ }^{4}$ The Mayo Clinic Cohort Study of Oophorectomy and Aging-2 (MOA-2) included a cohort of women who underwent bilateral oophorectomy and a cohort of age-matched referent women representative of the Olmsted County, MN population. All data collection was through the records-linkage system of the Rochester Epidemiology Project (REP) that has been described extensively elsewhere. $^{15-18}$

We used the electronic index of the REP to identify women who received a code from the International Classification of Diseases, ninth revision (ICD-9) for either unilateral $(65.3 \times$ and $65.4 \times)$ or bilateral $(65.5 \times$ and $65.6 \times)$ oophorectomy between 1 January 1988 and 31 December 2007 (20 years). We included women who underwent bilateral oophorectomy or a second unilateral oophorectomy before the onset of menopause and before reaching the age of 50 years, regardless of concurrent or prior hysterectomy. Although hysterectomy causes cessation of menses, women with prior hysterectomy were included because hysterectomy does not directly cause cessation of ovarian function. However, we excluded women who underwent oophorectomy for ovarian cancer (primary or metastatic), to treat another estrogen-sensitive malignancy (usually breast cancer), or because they had high genetic risk of cancer (eg, carriers of BRCA1 or BRCA2 variants). ${ }^{4}$
For each woman included in the bilateral oophorectomy cohort, we used the date of the surgery as an index date and selected via simple random sampling a woman from the Olmsted County population who was born in the same year ( \pm 1 year) and had not undergone bilateral oophorectomy before the index date. All women who met these criteria were considered eligible regardless of menopausal status, of any possible diseases or risk factors, and of prior hysterectomy or unilateral oophorectomy. The complete medical records of the women with oophorectomy and of the referent women were abstracted manually by a physician (LGR) or a trained nurse to confirm the oophorectomy status and to obtain extensive details about the surgery. Thus, the final classification of women was based on the findings at chart review. ${ }^{4}$

From these two cohorts, we excluded women who underwent oophorectomy at age 46-49 years (and the matched referent women) to restrict the study to premature or early surgical menopause. We also excluded women who did not have medical records dating back to age 15 years or earlier to ensure at least 4 years of concurrent capture of childhood experiences (age 15 to 19 years). Finally, we excluded women affected by severe intellectual disability because they could not self-report their childhood experiences. All of the complete matched pairs fulfilling the inclusion criteria were included for a total of 128 cases and 128 controls (figure 1). Based on a pilot study, this sample had adequate statistical power to test the primary hypothesis of the study and was compatible with our funding resources.

\section{Collection of data about adverse childhood or adult experiences}

The complete medical records of both cases and controls were manually abstracted by a physician (LGR) to retrieve from the narrative psychiatric and medical notes any reports of adverse experiences including abuse, violence, and neglect between birth and age 19 years, in particular those factors included in the Adverse Childhood Experience (ACE) score. ${ }^{19-21}$ The 10-item ACE score has been widely used to assess long-term effects of childhood adversity on later health and illness and was derived from an extensive list of survey questions used in the original ACE study, as described elsewhere. ${ }^{19-21}$ We derived an ACE score from information abstracted from the comprehensive medical records rather than from a patient interview. Online supplementary table 1 shows examples of the statements found in the medical records that corresponded to the 10 items of the ACE questionnaire. We also abstracted information about verbal or emotional, physical, or sexual abuse that occurred between age 19 and the index date. Women without medical record documentation of adverse childhood or adult experiences were considered free of adverse experiences (not exposed).

The abstractor did not have access to the list of women classified as cases or controls or to the structure 


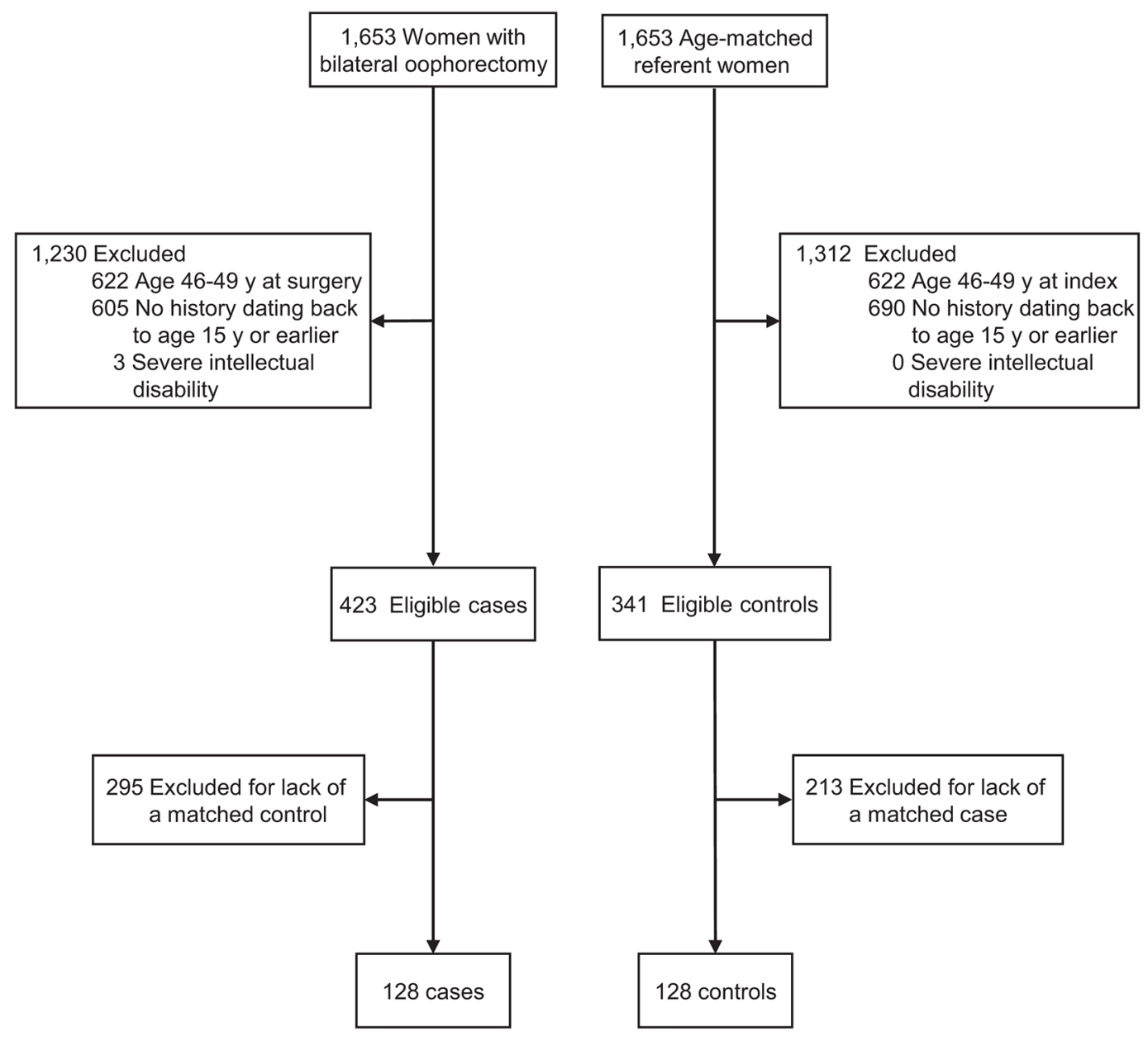

Figure 1 Flow charts for the identification of cases and controls. From the original cohorts of 1,653 women with bilateral oophorectomy and 1,653 referent women, we excluded women with oophorectomy at age 46-49 years, women with no medical records dating back to age 15 or earlier, and women with severe intellectual disability. Additional losses were due to the restriction to complete pairs in which both women had medical records dating back to age 15 years or earlier (exclusion of cases or controls without a matching pair). All of the 128 complete matched pairs fulfilling the inclusion criteria were included.

of matching. However, because it was not practical to keep the abstractor unaware of the surgical details in the records, we developed a manual of instructions to standardise the abstraction of data that were incomplete or required judgement. For example, we developed rules to assign the first occurrence of an adverse event to broad age ranges (birth through age 12 years vs age 13 through age 18 years). In addition, we assessed the intra-rater reliability of the abstractor (see below). All study procedures were approved by the institutional review boards of Mayo Clinic and Olmsted Medical Center.

\section{Reliability and validity}

A 2004 meta-analysis summarised the evidence about the reliability and validity of adult reporting of childhood sexual abuse, physical abuse, and physical or emotional neglect. Both men and women tended to under-report adverse childhood events, especially if their life experiences at the time of the study were positive. ${ }^{22}$ The test-retest reliability of the ACE questionnaire has been reported as adequate or good in one study. ${ }^{23}$ The ACE questionnaire (international version) has also been previously validated in Nigerian prisoners using the Childhood Trauma Questionnaire as a standard. ${ }^{24}$ We studied the intra-rater reliability of medical records abstraction of adverse childhood or adult experiences by having the abstractor (LGR) repeat the abstraction of a random sample of 20 records without access to the result of the initial abstraction (10 women who had at least one adverse experience any time before index date, and 10 women who did not; equal allocation by case-control status). The agreement was $90.0 \%$ (10 agreements positive and 8 agreements negative), with a kappa of $80.0 \%$ (95\% CI 54.2 to 100.0 ).

\section{Statistical analyses}

We estimated the OR and the $95 \%$ CI for each of the 10 items of the ACE score separately, for specific cut-off 
points of the ACE score, and for abuse during adulthood using conditional logistic regression models. We conducted three sets of analyses considering experiences occurring between birth and age 19 years (defined as childhood experiences), experiences of abuse occurring between age 19 years and the index date (defined as adulthood experiences), and experiences occurring any time between birth and the index date (cumulative experiences). Analyses were conducted overall and in strata defined by age at oophorectomy ( $<40$ vs 40 to 45 years) and by surgical indication (benign ovarian condition vs no ovarian indication).

For the primary analysis (ACE score $\geq 1$ ), we explored possible variables intervening along the causal pathway between the adverse experiences and oophorectomy (mediating variables), or possible confounding variables using bivariable and multivariable models. A variable was considered important if the OR for an ACE score $\geq 1$ was reduced $>10 \%$ by introducing the confounding or mediating variable in the model. We also explored all two-way interactions with an ACE score $\geq 1$ in the models.

Finally, we conducted two sets of sensitivity analyses: (1) a set in which we removed from the sample those control women who underwent bilateral oophorectomy after the index date and their matched cases; and (2) a set in which we restricted the sample to women who had medical records dating back to birth (for this set, we ignored the matching to increase the number of informative women). All analyses were performed using SAS V.9.4 (SAS Institute), and tests of statistical significance were conducted at the two-tailed alpha level of 0.05 .

\section{RESULTS}

\section{Study sample}

Figure 1 shows two flow charts for the selection of cases and controls from the original MOA-2 cohorts. ${ }^{4}$ The final sample included 128 matched case-control pairs in which both women had medical record information dating back to age 15 years or earlier. The median length of medical record information before the index date was 39.3 years in cases (IQR, 33.1-43.4 years) and 39.1 years in controls (IQR, 32.8-42.9 years, $\mathrm{p}=0.69$ ). In addition, 85 cases $(66.4 \%)$ and 74 controls $(57.8 \%)$ had medical records dating back to birth $(\mathrm{p}=0.16)$. Table 1 shows the characteristics of cases and controls at the index date. The two groups had different frequency of hysterectomy and unilateral oophorectomy. The bilateral oophorectomy was performed in conjunction with a hysterectomy in 107 women $(83.6 \%)$, and 19 additional women $(14.8 \%)$ had already undergone hysterectomy in a previous surgery. In addition, the women who underwent bilateral oophorectomy were more likely to have experienced suicidal ideation or attempt $(18.0 \%$ in cases vs $7.8 \%$ in controls; $\mathrm{p}=0.02$ ) and to have undergone an abdominal surgery $(71.1 \%$ in cases vs $59.4 \%$ in controls; $\mathrm{p}=0.049$ ).

\section{Case-control analyses}

Table 2 shows our case-control analyses for each of the 10 items in the ACE score separately, for selected cut-off points of the ACE score, and for abuse during adulthood. In analyses restricted to childhood events, 8 of the 10 items had an OR greater than 1.0, and the OR reached statistical significance for verbal or emotional abuse, physical abuse, and substance abuse in the household. The association was also statistically significant for any abuse in childhood. The OR for an ACE score $\geq 1$ was 3.23 (95\% CI 1.73 to $6.02 ; \mathrm{p}<0.001$ ), and childhood physical abuse had the strongest association with an OR of 5.75 (95\% CI 1.99 to 16.63 ; $\mathrm{p}=0.001$ ). In analyses for cumulative experiences, only physical abuse reached statistical significance. Figure 2 shows the OR and CIs for selected analyses derived from table 2. The results are shown for adverse experiences occurring in childhood, in adulthood, and cumulatively at any time before the index date.

Supplementary table 2 shows the characteristics of each of the 10 ACE items in cases and controls. Details are provided for the occurrence of repeated experiences, the age at the first experience, and the perpetrator of the abuse (when applicable). For many of the 10 adverse childhood experiences, the cases had higher frequency of repetition (multiple episodes) and younger age at the time of the first episode. For example, for verbal or emotional abuse, the abuse was repeated in $33.6 \%$ of cases but only in $21.1 \%$ of controls $(p=0.02)$. The first abuse event was before age 13 years in $20.3 \%$ of cases but only $7.8 \%$ of controls $(\mathrm{p}=0.01)$. The father was the perpetrator in $28.1 \%$ of cases and $9.4 \%$ of controls $(\mathrm{p}<0.001)$.

Table 3 summarises our case-control analyses stratified by age at the time of bilateral oophorectomy or index date for the referent women. In analyses restricted to childhood experiences, 5 of the 10 ACE score items had an OR greater in women in the $<40$ year stratum and the OR for physical abuse reached statistical significance within the $<40$ year stratum. However, none of these differences reached statistical significance in the comparison across age strata (tests for interaction). An ACE score $\geq 4$ was associated with an OR of 6.00 (95\% CI 1.34 to 26.81, $\mathrm{p}=0.02)$ in the $<40$-year stratum compared with 0.89 (95\% CI 0.34 to $2.30 ; \mathrm{p}=0.81$ ) in the 40- to 45-year stratum, and the difference across age strata was statistically significant $(\mathrm{p}=0.03)$.

In analyses of abuse experiences in adulthood, the OR reached statistical significance for women in the $<40$-year stratum for physical abuse (OR=4.33; 95\% CI 1.23 to 15.21 ; $\mathrm{p}=0.02$ ), and the difference across age strata was statistically significant $(p=0.02)$. In analyses for cumulative experiences, the OR reached statistical significance for women in the $<40$-year stratum for physical abuse $(\mathrm{OR}=8.50 ; 95 \% \mathrm{CI}$ 1.96 to $36.79 ; \mathrm{p}=0.004)$ and any abuse $(\mathrm{OR}=2.43 ; 95 \% \mathrm{CI}$ 1.01 to $5.86 ; \mathrm{p}=0.048)$. The difference across age strata was significant for physical abuse $(\mathrm{p}=0.009)$.

Table 4 summarises our case-control analyses stratified by indication for the oophorectomy. In analyses restricted to childhood events, 6 of the 10 ACE score items had an OR greater in women without an ovarian indication for 
Table 1 Characteristics of cases and controls at the time of bilateral oophorectomy or at index date

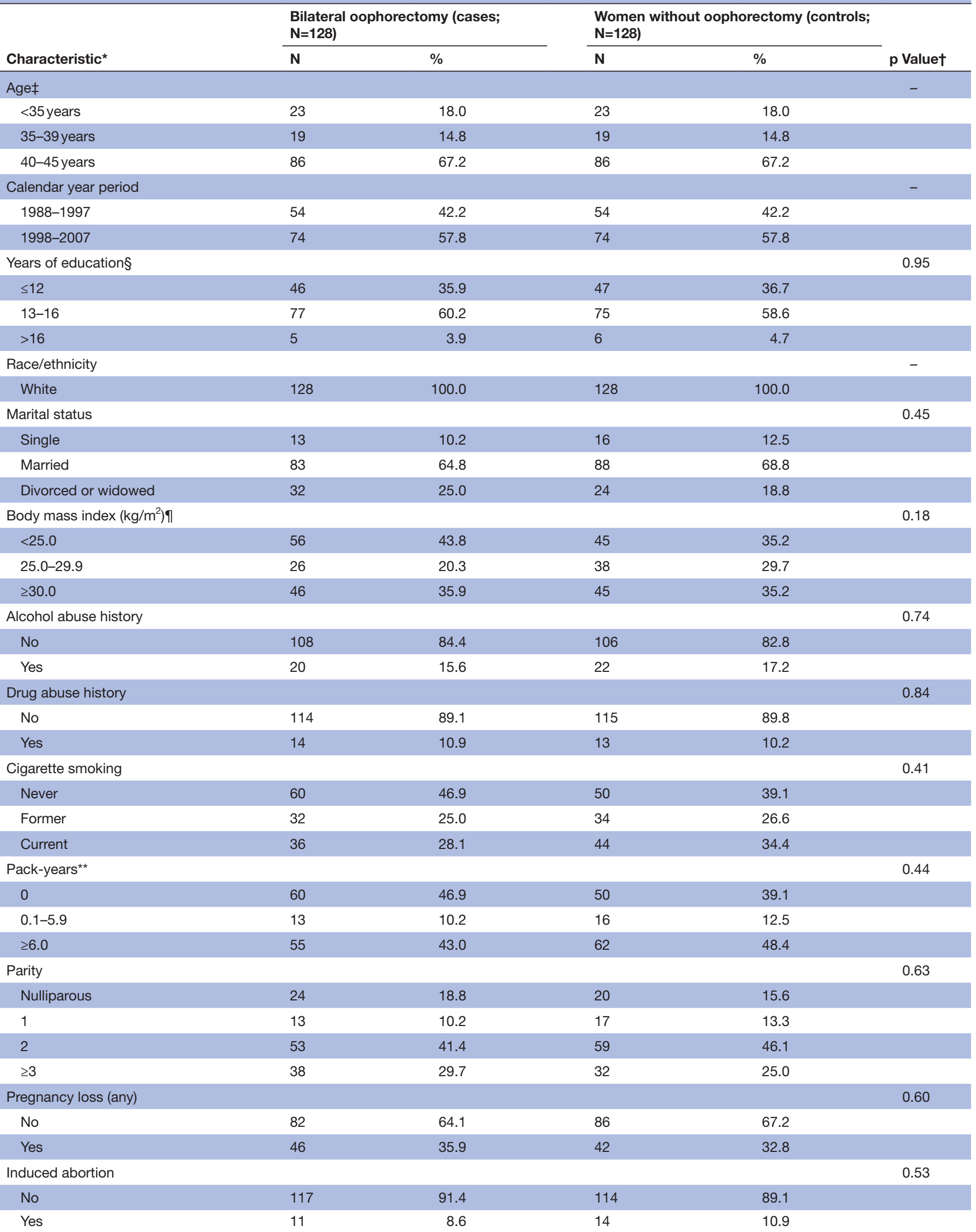


Open Access

Table 1 Continued

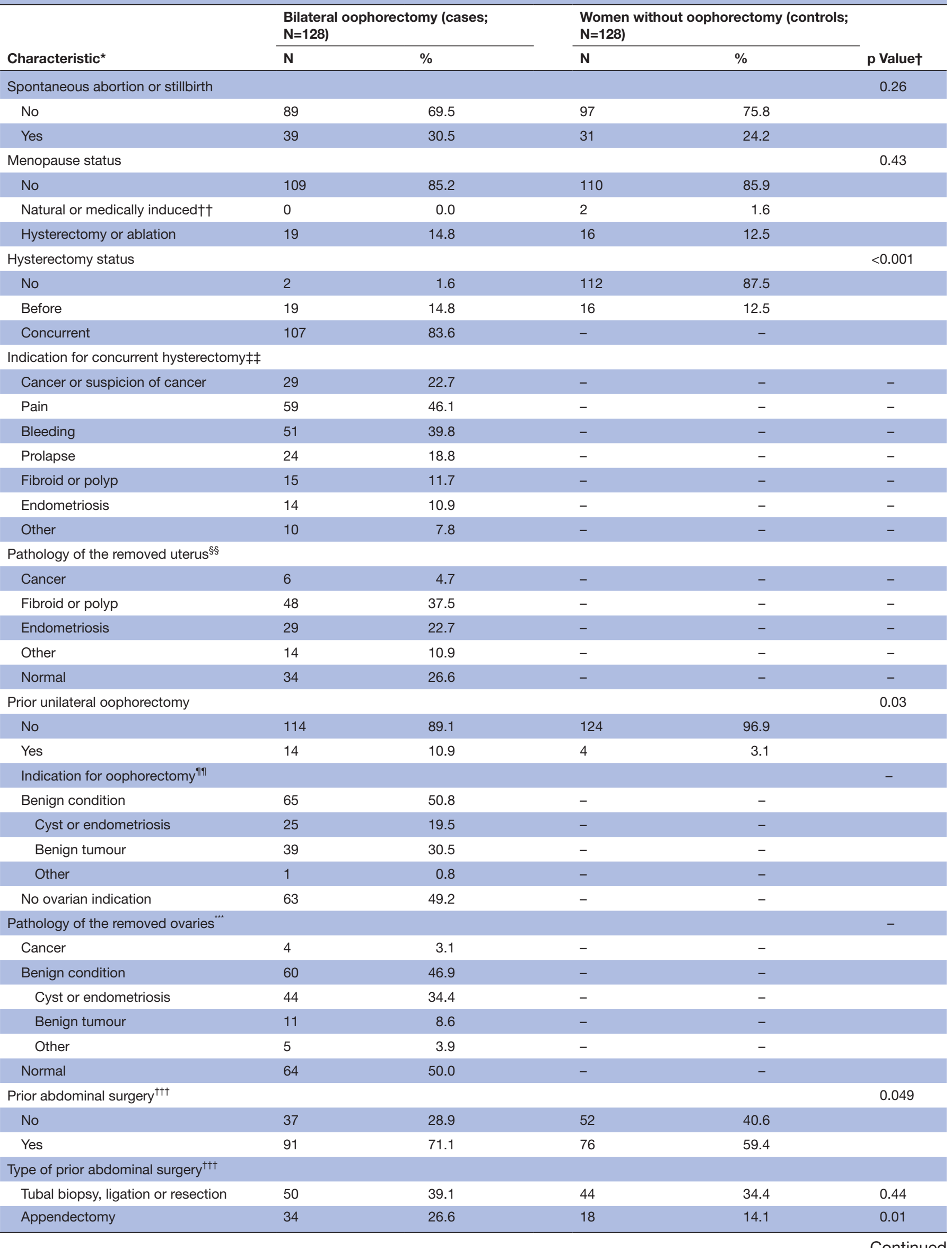


Table 1 Continued

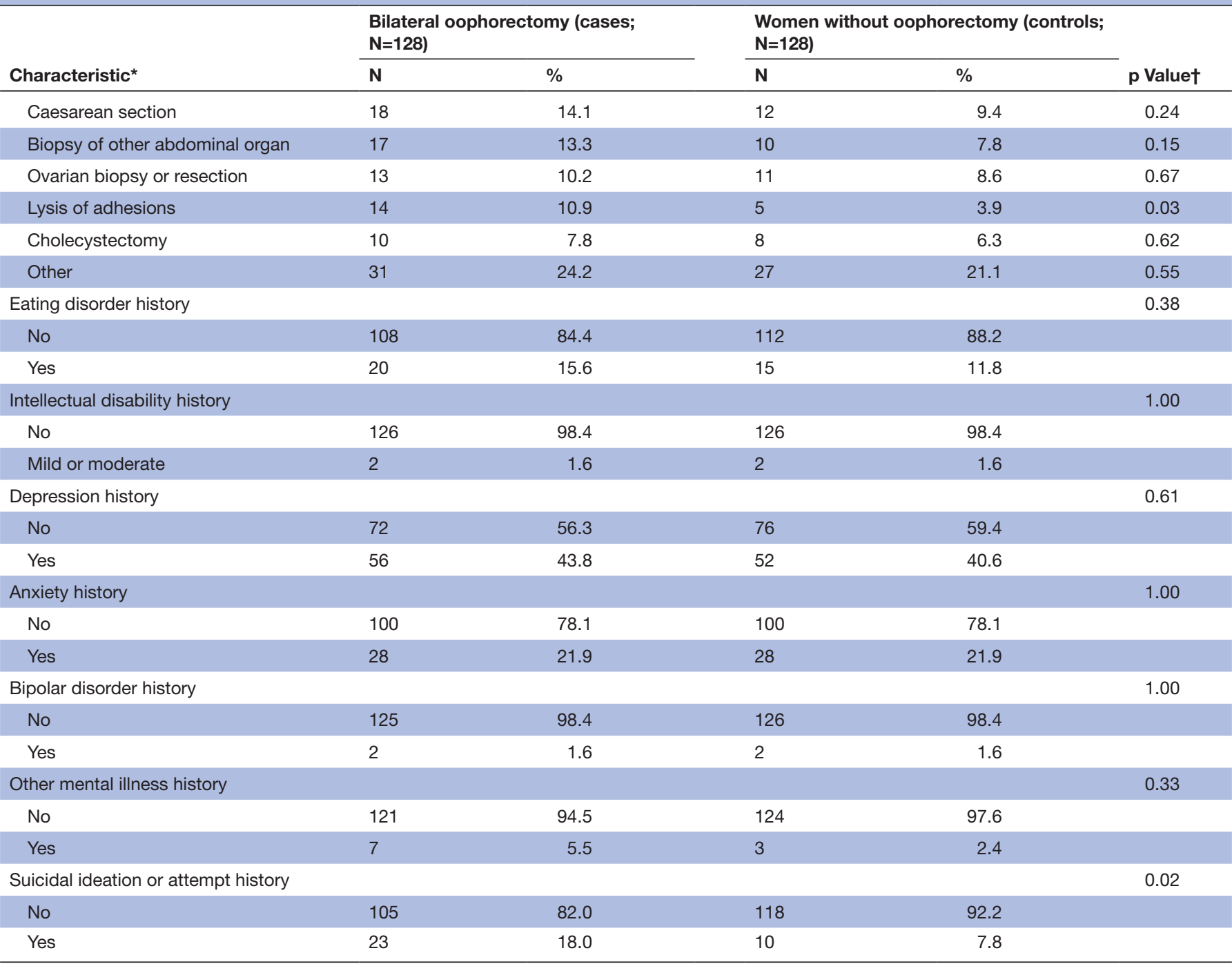

*Women with unknown data were not included in the tests for differences between the groups: one control woman had unknown eating disorder status, one woman with oophorectomy had unknown bipolar disorder status, and one control woman had unknown other mental illness status.

†The $p$ values were calculated using chi-squared tests or Fisher's exact tests.

$\ddagger$ Age at bilateral oophorectomy was stratified using conventional definitions of premature menopause ( $<40$ years; further broken down into $<35$ years and 35 to 39 years), and early menopause ( 40 to 45 years). ${ }^{4}$

$\S$ All women had at least 9 years of education.

|Analyses considering body mass index as a continuous variable were also not significant: median 26.1 (IQR 23.0-32.6) in cases and 27.3 (IQR 23.231.8) in controls; $p=0.57$.

${ }^{* *}$ Pack-years of cigarette smoking were stratified using tertiles calculated after combining the complete bilateral oophorectomy and referent women cohorts, as shown in our previous publication. ${ }^{4}$

††Menopause due to chemotherapy or radiation therapy.

¥¥The indication was listed by the gynaecologist in the medical record at the time of the surgery. Each woman may have more than one indication recorded. Cancer or suspicion of cancer includes women with cervical or endometrial cancers either confirmed through biopsy or other testing, or suspected based on abnormal results of Pap test or presence of pelvic masses. Other indications included anaemia, family history of endometrial cancers, and menstrual migraine headaches. The per cents refer to the total number of women who underwent bilateral oophorectomy ( $\mathrm{n}=128)$. $\S \S$ The pathology results were determined by a pathologist following the surgery. Each woman may have more than one pathology result recorded. Other pathology results included adenomyosis, cervical metaplasia, and mild cervical intraepithelial neoplasia. The per cents refer to the total number of women who underwent bilateral oophorectomy $(n=128)$.

IीThe indication was listed by the gynaecologist in the medical record at the time of oophorectomy. However, some of these indications are questionable from our current perspective. No ovarian indication refers to women without a malignant or benign ovarian condition. Historically, the terms 'prophylactic', 'elective', or 'incidental' oophorectomy were used; however, we avoided these terms. For women with different indications in the two ovaries, we reported the most severe indication. The per cents refer to the total number of women who underwent bilateral oophorectomy ( $\mathrm{n}=128)$. ${ }^{* \star \star}$ The pathology results were determined by a pathologist following the surgery. For women with different pathology in the two ovaries, we reported the most severe pathology. Women with malignancy as the indication for oophorectomy were excluded, however, some women with benign ovarian indication or no ovarian indication had ovarian malignancy or metastasis discovered at pathology.

$\dagger † \dagger$ Excluding prior hysterectomy or unilateral oophorectomy. Listed in order from most frequent to least frequent. Each woman may have more than one type of prior abdominal surgery. We included biopsies taken from abdominal mass, liver, intestine, cervix, or uterus. Other types of abdominal surgery included bladder excision or repair, conisation of cervix, gastric bypass, gastrostomy, hernia repair, laparotomy, nephrectomy, prolapse repair, splenectomy, tubal excision, uterine excision, and other abdominal surgeries. 
Table 2 Case-control analyses for adverse childhood experiences or abuse in adulthood

\begin{tabular}{|c|c|c|c|c|c|c|}
\hline \multirow[b]{2}{*}{ Adverse experience } & \multicolumn{2}{|c|}{$\begin{array}{l}\text { Bilateral } \\
\text { oophorectomy } \\
\text { (cases; } \mathrm{N}=128 \text { ) }\end{array}$} & \multicolumn{2}{|c|}{$\begin{array}{l}\text { Women without } \\
\text { oophorectomy } \\
\text { (controls; } \mathrm{N}=128 \text { ) }\end{array}$} & \multicolumn{2}{|c|}{ Case-control analyses ${ }^{*}$} \\
\hline & $\mathbf{N}$ & $\%$ & $\mathbf{N}$ & $\%$ & OR $(95 \% \mathrm{Cl})$ & p Value \\
\hline \multicolumn{7}{|l|}{ Childhood (age $<19$ years) } \\
\hline Q1: verbal or emotional abuse & 47 & 36.7 & 27 & 21.1 & 2.05 (1.19 to 3.55$)$ & 0.01 \\
\hline Q2: physical abuse & 25 & 19.5 & 6 & 4.7 & 5.75 (1.99 to 16.63$)$ & 0.001 \\
\hline Q3: sexual abuse & 10 & 7.8 & 6 & 4.7 & 1.67 (0.61 to 4.59$)$ & 0.32 \\
\hline Q4: emotional neglect & 23 & 18.0 & 19 & 14.8 & 1.24 (0.65 to 2.34$)$ & 0.52 \\
\hline Q5: physical neglect & 6 & 4.7 & 11 & 8.6 & $0.38(0.10$ to 1.41$)$ & 0.15 \\
\hline Q6: parental separation & 22 & 17.2 & 16 & 12.5 & $1.50(0.72$ to 3.11$)$ & 0.28 \\
\hline Q7: witnessed domestic violence & 7 & 5.5 & 4 & 3.1 & 1.75 (0.51 to 5.98$)$ & 0.37 \\
\hline Q8: substance abuse in household & 61 & 47.7 & 44 & 34.4 & 1.85 (1.07 to 3.19$)$ & 0.03 \\
\hline Q9: mental illness in household & 46 & 35.9 & 39 & 30.5 & $1.33(0.76$ to 2.35$)$ & 0.32 \\
\hline Q10: incarceration & 1 & 0.8 & 0 & 0.0 & - & - \\
\hline Any abuse (verbal or emotional, physical, sexual) & 52 & 40.6 & 29 & 22.7 & 2.21 (1.29 to 3.80$)$ & 0.004 \\
\hline ACE score $\geq 1$ & 101 & 78.9 & 72 & 56.3 & 3.23 (1.73 to 6.02$)$ & $<0.001$ \\
\hline ACE score $\geq 2$ & 67 & 52.3 & 53 & 41.4 & 1.70 (0.98 to 2.95$)$ & 0.06 \\
\hline ACE score $\geq 3$ & 39 & 30.5 & 27 & 21.1 & 1.60 (0.92 to 2.80$)$ & 0.10 \\
\hline ACE score $\geq 4$ & 22 & 17.2 & 13 & 10.2 & $1.82(0.87$ to 3.79$)$ & 0.11 \\
\hline \multicolumn{7}{|l|}{ ACE score } \\
\hline 0 & 27 & 21.1 & 56 & 43.8 & (reference) & \\
\hline 1 & 34 & 26.6 & 19 & 14.8 & 4.17 (1.85 to 9.40$)$ & $<0.001$ \\
\hline 2 & 28 & 21.9 & 26 & 20.3 & 2.54 (1.19 to 5.41$)$ & 0.02 \\
\hline 3 & 17 & 13.3 & 14 & 10.9 & 2.73 (1.15 to 6.51$)$ & 0.02 \\
\hline$\geq 4$ & 22 & 17.2 & 13 & 10.2 & 4.45 (1.75 to 11.29$)$ & 0.002 \\
\hline \multicolumn{7}{|l|}{ Adulthood (age 19 to index date) } \\
\hline Verbal or emotional abuse & 40 & 31.3 & 43 & 33.6 & $0.90(0.54$ to 1.51$)$ & 0.70 \\
\hline Physical abuse & 25 & 19.5 & 18 & 14.1 & 1.47 (0.76 to 2.83$)$ & 0.25 \\
\hline Sexual abuse & 7 & 5.5 & 2 & 1.6 & $3.50(0.73$ to 16.85$)$ & 0.12 \\
\hline Any abuse (verbal or emotional, physical, sexual) & 45 & 35.2 & 45 & 35.2 & $1.00(0.61$ to 1.65$)$ & 1.00 \\
\hline \multicolumn{7}{|l|}{ Cumulative experience from birth to index date } \\
\hline Verbal or emotional abuse & 63 & 49.2 & 51 & 39.8 & 1.44 (0.88 to 2.36$)$ & 0.14 \\
\hline Physical abuse & 35 & 27.3 & 21 & 16.4 & $1.93(1.04$ to 3.61$)$ & 0.04 \\
\hline Sexual abuse & 14 & 10.9 & 7 & 5.5 & 2.00 (0.81 to 4.96$)$ & 0.13 \\
\hline Any abuse (verbal or emotional, physical, sexual) & 68 & 53.1 & 52 & 40.6 & 1.62 (0.99 to 2.63$)$ & 0.05 \\
\hline
\end{tabular}

*The ORs, Cls and $p$ values were calculated using conditional logistic regression models (matched pairs).

ACE, Adverse Childhood Experiences; OR, odds ratio; Cl, confidence interval.

oophorectomy. The difference across strata was statistically significant for sexual abuse (OR=8.00; 95\% CI 1.00 to 63.96 vs $\mathrm{OR}=0.40,95 \% \mathrm{CI} 0.08$ to 2.06 ; $\mathrm{p}$ for interaction $=0.03$ ) and emotional neglect $(\mathrm{OR}=4.67 ; 95 \%$ CI 1.34 to 16.24 vs $\mathrm{OR}=0.50 ; 95 \%$ CI 0.20 to $1.24 ; \mathrm{p}$ for interaction $=0.005)$. The difference across strata was also significant for any childhood abuse combined, for an ACE score $\geq 3$, and for an ACE score $\geq 4$. In analyses for cumulative experiences, the OR for sexual abuse and for any abuse combined was significantly greater in women without an ovarian indication.
Table 5 summarises our case-control analyses exploring possible confounding variables or mediating variables along the causal pathway. When we added to the single-variable model for an ACE score $\geq 1$ several variables one at a time (bivariable models), the OR did not change noticeably for any. In addition, the OR did not change noticeably in a multivariable model including all of the additional psychosocial or medical variables considered at the same time. Finally, none of the two-way interactions with an ACE score $\geq 1$ were significant in any of these models. 


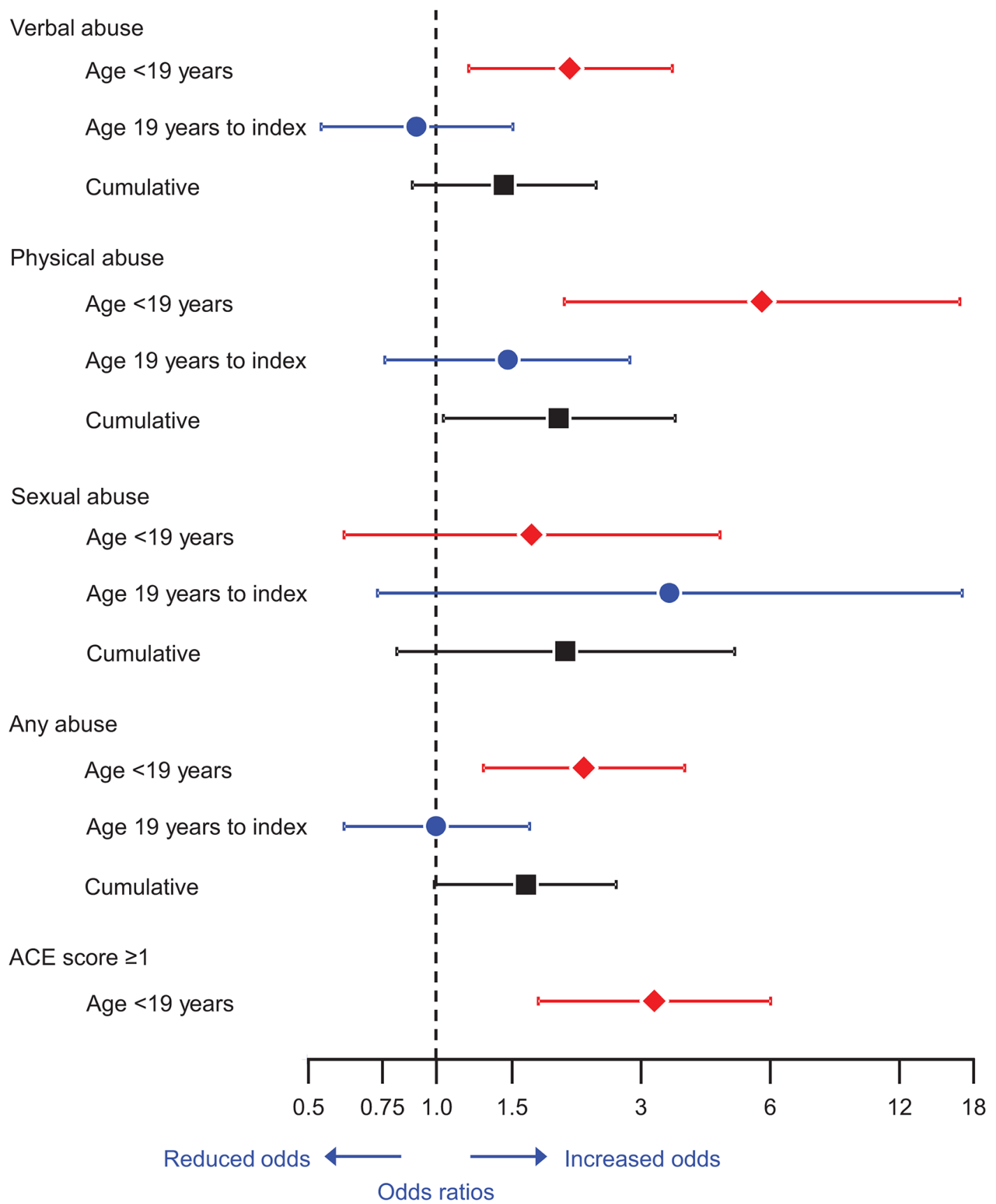

Figure 2 ORs and 95\% Cls for selected adverse childhood experiences and abuse in adulthood. Analyses are shown for the time period from birth to age 19 years, from age 19 to the index date, and cumulatively at any time before the index date. ACE, Adverse Childhood Experiences; OR, odds ratio; Cl, confidence interval.

\section{Sensitivity analyses}

Because our case-control study was derived from a cohort study, we did have information about gynaecological surgeries occurring after the index date in controls. ${ }^{4}$ Therefore, we conducted a first set of sensitivity analyses after removing from the sample nine control women who underwent bilateral oophorectomy after the index date and their nine matched cases. In general, the results were more extreme (greater ORs) in this set of sensitivity analyses (see online supplementary table 3 ). The second set of sensitivity analyses, restricted to 85 cases and 74 controls who had medical records dating back to birth, showed results similar to those in the unrestricted sample (see online supplementary table 4 ).

\section{DISCUSSION}

\section{Principal findings}

We observed a strong association of bilateral oophorectomy before age 46 years with verbal or emotional 
Table 3 Case-control analyses for adverse childhood experiences or abuse in adulthood-by age at oophorectomy strata

\begin{tabular}{lll}
$\begin{array}{l}\text { Bilateral oophorectomy } \\
\text { (cases; N=42; 86) }\end{array}$ & $\begin{array}{l}\text { Women without } \\
\text { oophorectomy } \\
\text { (controls; } \mathrm{N}=42 ; 86)^{*}\end{array}$ \\
\cline { 1 - 3 }
\end{tabular}

Case-control analyses†

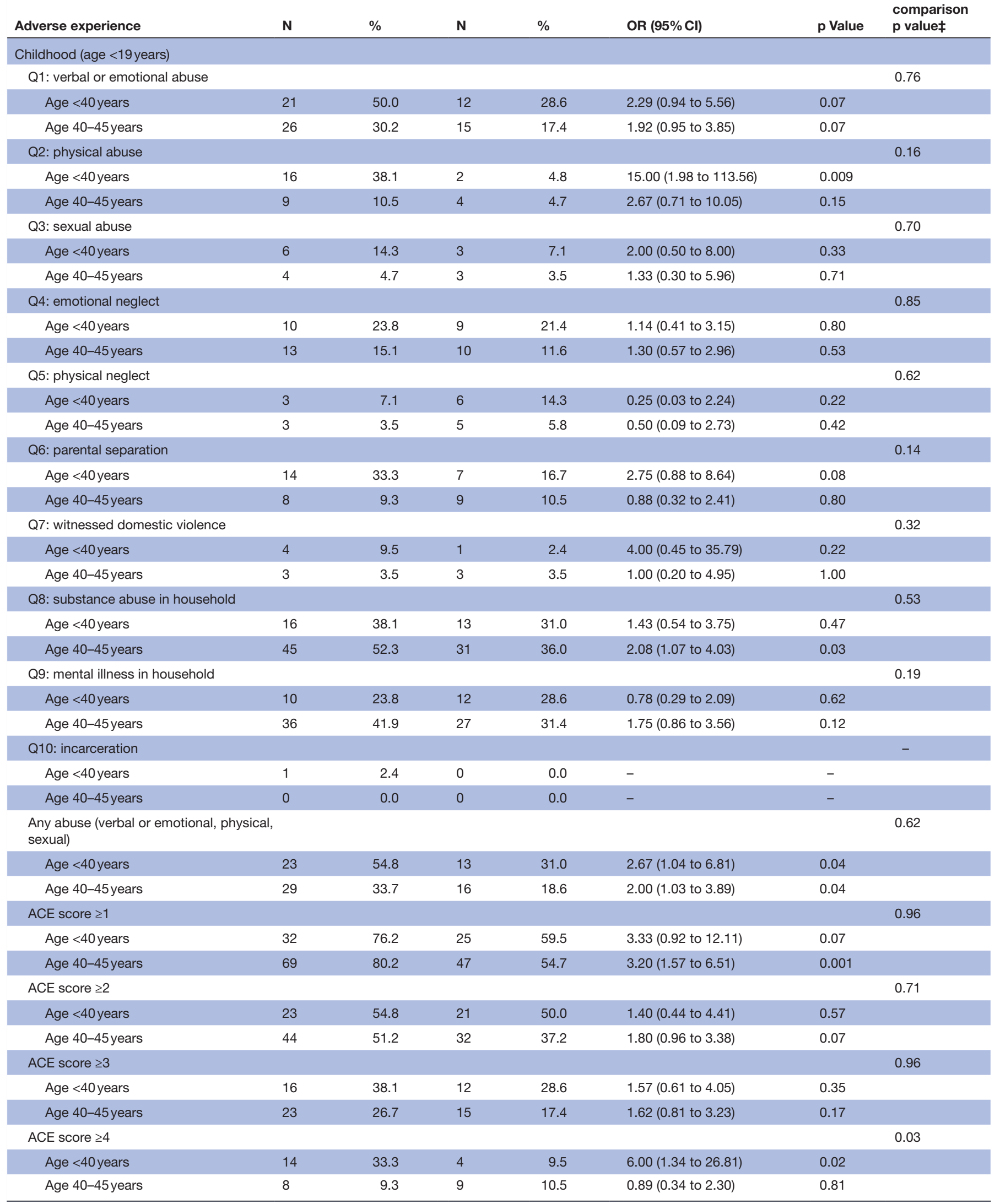


Table 3 Continued

\begin{tabular}{|c|c|c|c|c|c|c|c|}
\hline \multirow[b]{2}{*}{ Adverse experience } & \multicolumn{2}{|c|}{$\begin{array}{l}\text { Bilateral oophorectomy } \\
\text { (cases; } \mathrm{N}=42 ; 86)^{*}\end{array}$} & \multicolumn{2}{|c|}{$\begin{array}{l}\text { Women without } \\
\text { oophorectomy } \\
\text { (controls; N=42; 86)* }\end{array}$} & \multicolumn{3}{|c|}{ Case-control analyses $\dagger$} \\
\hline & $\mathbf{N}$ & $\%$ & $\mathbf{N}$ & $\%$ & OR $(95 \% \mathrm{Cl})$ & p Value & $\begin{array}{l}\text { Strata } \\
\text { comparison } \\
\text { p valueł }\end{array}$ \\
\hline \multicolumn{8}{|l|}{ Adulthood (age 19 to index date) } \\
\hline Verbal or emotional abuse & & & & & & & 0.06 \\
\hline Age $40-45$ years & 23 & 26.7 & 32 & 37.2 & 0.63 (0.33 to 1.19$)$ & 0.15 & \\
\hline Physical abuse & & & & & & & 0.02 \\
\hline Age $<40$ years & 15 & 35.7 & 5 & 11.9 & $4.33(1.23$ to 15.21$)$ & 0.02 & \\
\hline Age $40-45$ years & 10 & 11.6 & 13 & 15.1 & 0.75 (0.32 to 1.78$)$ & 0.51 & \\
\hline Sexual abuse & & & & & & & - \\
\hline Age $<40$ years & 20 & 47.6 & 13 & 31.0 & 2.00 (0.81 to 4.96$)$ & 0.13 & \\
\hline Age 40-45years & 25 & 29.1 & 32 & 37.2 & 0.71 (0.38 to 1.32$)$ & 0.28 & \\
\hline \multicolumn{8}{|l|}{ Cumulative experience from birth to index date } \\
\hline Verbal or emotional abuse & & & & & & & 0.25 \\
\hline Age $<40$ years & 26 & 61.9 & 17 & 40.5 & 2.12 (0.92 to 4.92$)$ & 0.08 & \\
\hline Age $40-45$ years & 37 & 43.0 & 34 & 39.5 & 1.16 (0.63 to 2.14$)$ & 0.64 & \\
\hline Physical abuse & & & & & & & 0.009 \\
\hline Age $<40$ years & 21 & 50.0 & 6 & 14.3 & 8.50 (1.96 to 36.79$)$ & 0.004 & \\
\hline Age $40-45$ years & 14 & 16.3 & 15 & 17.4 & 0.92 (0.42 to 2.02 ) & 0.84 & \\
\hline
\end{tabular}

*Percentages are calculated from the total number of the respective case or control group. The younger age strata contains 42 women who underwent bilateral oophorectomy at age $<40$ years ( 24 for benign ovarian conditions, 18 for no ovarian indication) and 42 controls. The older age stratum contains 86 women who underwent bilateral oophorectomy at age $40-45$ years ( 41 for benign ovarian conditions, 45 for no ovarian indication) and 86 controls.

†The ORs, Cls, and $\mathrm{p}$ values were calculated using conditional logistic regression models (matched pairs) within each age stratum separately.

$\ddagger$ The $\mathrm{p}$ values were calculated using conditional logistic regression models for both age strata combined, and represent statistical comparisons of the ORs and Cls across the two age strata.

ACE, Adverse Childhood Experiences; OR, odds ratio; $\mathrm{Cl}$, confidence interval.

abuse, physical abuse, any abuse, substance abuse in the household, and with an ACE score $\geq 1$ experienced before age 19 years. In addition, we observed a strong association with physical abuse experienced during adulthood in women who underwent oophorectomy before age 40 years. In general, the associations were greater in women who underwent bilateral oophorectomy at a younger age and in women who did not have a specified ovarian indication for the oophorectomy. These associations were not mediated or confounded by lower education, negative marital or reproductive experiences, smoking or substance abuse, or by diagnoses of anxiety, depression, eating disorders, obesity, or suicide attempt or ideation.

\section{Strengths and limitations}

To our knowledge, this is the first study to investigate the possible association of adverse childhood experiences or abuse during adulthood with bilateral oophorectomy; however, previous studies addressed the association of adverse childhood or adult experiences with later risk of several diseases. ${ }^{1925-27}$ One previous study focused on the association between sexual assault and hysterectomy, with or without concurrent bilateral oophorectomy. ${ }^{28}$ The focus of that study was different from our study because a sizeable percent of women in the general population undergo hysterectomy with ovarian conservation, and these women may have different long-term effects of hysterectomy on morbidity and mortality. 
Table 4 Case-control analyses for adverse childhood experiences or abuse in adulthood-stratified by oophorectomy indication

\begin{tabular}{llll}
$\begin{array}{l}\text { Bilateral } \\
\text { oophorectomy } \\
\text { (cases; } \mathrm{N}=65 ; 63)^{*}\end{array}$ & $\begin{array}{l}\text { Women without } \\
\text { oophorectomy } \\
\text { (controls; } \mathrm{N}=65 ; 63)^{*}\end{array}$ & $\begin{array}{l}\text { Case-control } \\
\text { analyses } \dagger\end{array}$ \\
\cline { 1 - 2 }
\end{tabular}

\begin{tabular}{|c|c|c|c|c|c|c|c|}
\hline Adverse experience & $\mathbf{N}$ & $\%$ & $\mathbf{N}$ & $\%$ & OR $(95 \% \mathrm{Cl})$ & p Value & $\begin{array}{l}\text { comparison } \\
\text { p value } \neq\end{array}$ \\
\hline \multicolumn{8}{|l|}{ Childhood (age <19years) } \\
\hline Q1: verbal or emotional abuse & & & & & & & 0.05 \\
\hline Benign ovarian condition" & 19 & 29.2 & 17 & 26.2 & 1.17 (0.54 to 2.52$)$ & 0.70 & \\
\hline No ovarian indication $\$$ & 28 & 44.4 & 10 & 15.9 & 3.57 (1.54 to 8.26$)$ & 0.003 & \\
\hline Q2: physical abuse & & & & & & & 0.81 \\
\hline Benign ovarian condition? & 11 & 16.9 & 3 & 4.6 & 5.00 (1.10 to 22.82$)$ & 0.04 & \\
\hline No ovarian indication ${ }^{\S}$ & 14 & 22.2 & 3 & 4.8 & 6.50 (1.47 to 28.80$)$ & 0.01 & \\
\hline Q3: sexual abuse & & & & & & & 0.03 \\
\hline Benign ovarian condition? & 2 & 3.1 & 5 & 7.7 & 0.40 (0.08 to 2.06$)$ & 0.27 & \\
\hline No ovarian indication ${ }^{\S}$ & 8 & 12.7 & 1 & 1.6 & 8.00 (1.00 to 63.96$)$ & 0.049 & \\
\hline Q4: emotional neglect & & & & & & & 0.005 \\
\hline Benign ovarian condition" & 9 & 13.8 & 16 & 24.6 & $0.50(0.20$ to 1.24$)$ & 0.13 & \\
\hline No ovarian indication $\$$ & 14 & 22.2 & 3 & 4.8 & 4.67 (1.34 to 16.24$)$ & 0.02 & \\
\hline Q5: physical neglect & & & & & & & - \\
\hline Benign ovarian condition" & 2 & 3.1 & 8 & 12.3 & $-{ }^{* *}$ & - & \\
\hline No ovarian indication ${ }^{\S}$ & 4 & 6.3 & 3 & 4.8 & $1.50(0.25$ to 8.98$)$ & 0.66 & \\
\hline Q6: parental separation & & & & & & & 0.65 \\
\hline Benign ovarian condition" & 11 & 16.9 & 9 & 13.8 & 1.29 (0.48 to 3.45$)$ & 0.62 & \\
\hline No ovarian indication ${ }^{\S}$ & 11 & 17.5 & 7 & 11.1 & $1.80(0.60$ to 5.37$)$ & 0.29 & \\
\hline Q7: witnessed domestic violence & & & & & & & - \\
\hline Benign ovarian condition? & 4 & 6.2 & 4 & 6.2 & $1.00(0.25$ to 4.00$)$ & 1.00 & \\
\hline No ovarian indication $\$$ & 3 & 4.8 & 0 & 0.0 & - & - & \\
\hline Q8: substance abuse in household & & & & & & & 0.23 \\
\hline Benign ovarian condition" & 27 & 41.5 & 23 & 35.4 & 1.33 (0.63 to 2.82$)$ & 0.45 & \\
\hline No ovarian indication ${ }^{\S}$ & 34 & 54.0 & 21 & 33.3 & 2.62 (1.16 to 5.93$)$ & 0.02 & \\
\hline Q9: mental illness in household & & & & & & & 0.51 \\
\hline Benign ovarian condition" & 26 & 40.0 & 20 & 30.8 & 1.60 (0.73 to 3.53$)$ & 0.24 & \\
\hline No ovarian indication ${ }^{\S}$ & 20 & 31.7 & 19 & 30.2 & 1.09 (0.48 to 2.47$)$ & 0.83 & \\
\hline Q10: incarceration & & & & & & & - \\
\hline Benign ovarian condition & 0 & 0.0 & 0 & 0.0 & - & - & \\
\hline No ovarian indication $\S$ & 1 & 1.6 & 0 & 0.0 & - & - & \\
\hline $\begin{array}{l}\text { Any abuse (verbal or emotional, } \\
\text { physical, sexual) }\end{array}$ & & & & & & & 0.01 \\
\hline Benign ovarian condition? & 20 & 30.8 & 19 & 29.2 & $1.08(0.51$ to 2.29$)$ & 0.85 & \\
\hline No ovarian indication ${ }^{\S}$ & 32 & 50.8 & 10 & 15.9 & 4.67 (1.93 to 11.27$)$ & $<0.001$ & \\
\hline ACE score $\geq 1$ & & & & & & & 0.72 \\
\hline Benign ovarian condition" & 49 & 75.4 & 38 & 58.5 & $2.83(1.12$ to 7.19$)$ & 0.03 & \\
\hline No ovarian indication ${ }^{\S}$ & 52 & 82.5 & 34 & 54.0 & 3.57 (1.54 to 8.26$)$ & 0.003 & \\
\hline ACE score $\geq 2$ & & & & & & & 0.33 \\
\hline Benign ovarian condition & 34 & 52.3 & 31 & 47.7 & 1.27 (0.58 to 2.80$)$ & 0.55 & \\
\hline No ovarian indication $\$$ & 33 & 52.4 & 22 & 34.9 & 2.22 (1.01 to 4.88$)$ & 0.047 & \\
\hline ACE score $\geq 3$ & & & & & & & 0.01 \\
\hline Benign ovarian condition" & 18 & 27.7 & 20 & 30.8 & $0.88(0.43$ to 1.79$)$ & 0.72 & \\
\hline
\end{tabular}

Continued 
Table 4 Continued

\begin{tabular}{llll}
$\begin{array}{l}\text { Bilateral } \\
\text { oophorectomy } \\
\text { (cases; } \mathrm{N}=65 ; 63)^{*}\end{array}$ & $\begin{array}{l}\text { Women without } \\
\text { oophorectomy } \\
(\text { controls; } \mathrm{N}=65 ; 63)^{*}\end{array}$ & $\begin{array}{l}\text { Case-control } \\
\text { analyses } \dagger\end{array}$ \\
\cline { 1 - 2 } \cline { 1 - 2 } & &
\end{tabular}

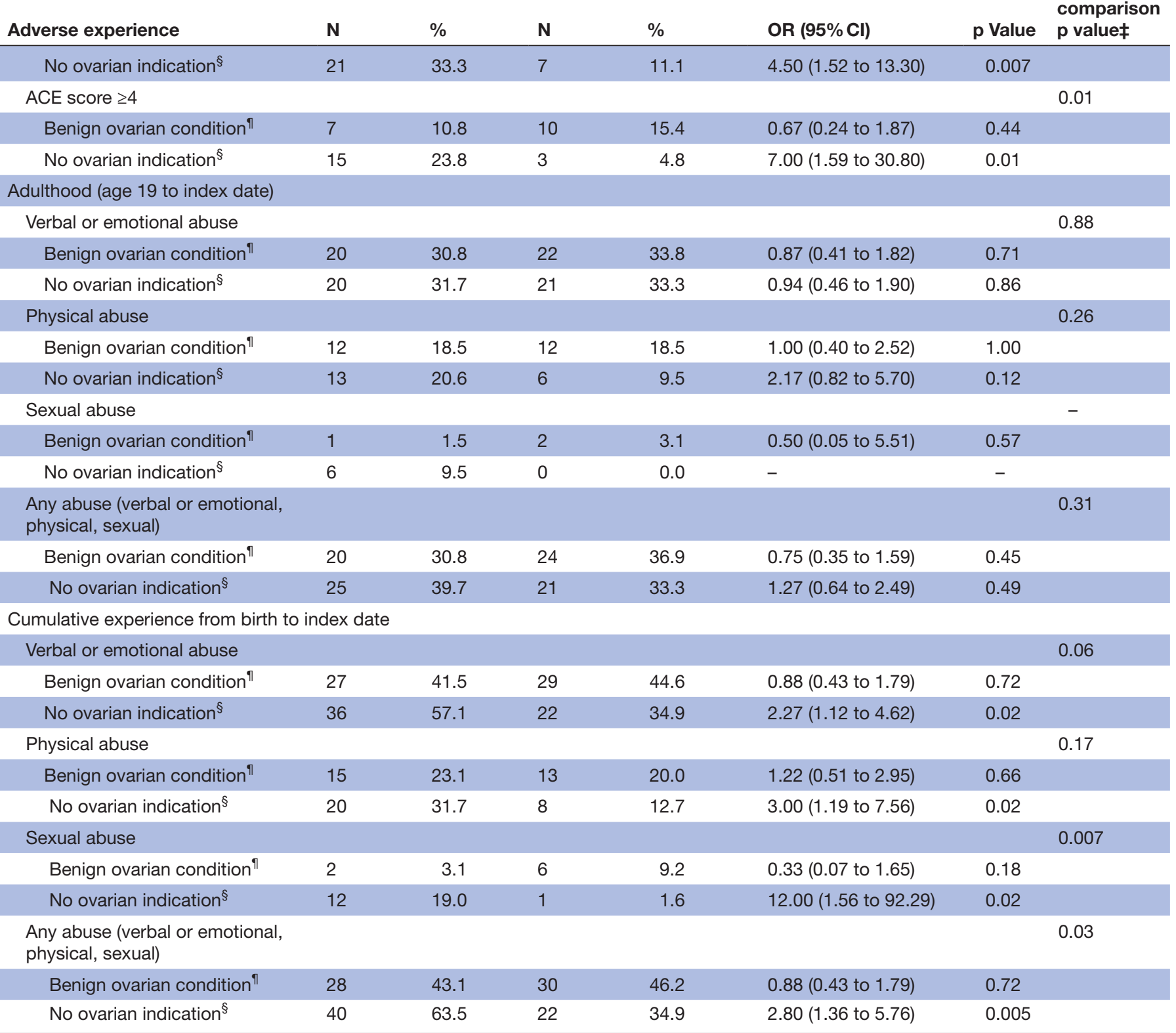

${ }^{*}$ Percentages are calculated from the total number of the respective case or control group. The first strata contains 65 women who underwent bilateral oophorectomy for benign ovarian conditions ( 24 at age $<40$ years, 41 at age $40-45$ years) and 65 controls. The second strata contains 63 women who underwent bilateral oophorectomy for no ovarian conditions (18 at age <40 years, 45 at age $40-45$ years) and 63 controls.

†The ORs, Cls, and $\mathrm{p}$ values were calculated using conditional logistic regression models (matched pairs) within each indication stratum separately.

‡The $p$ values were calculated using conditional logistic regression models for both indication strata combined, and represent statistical comparisons of the ORs and Cls across the two indication strata.

१The benign ovarian condition (eg, cyst, endometriosis, benign tumour, etc) was listed by the gynaecologist in the medical record at the time of oophorectomy. However, some of these indications are questionable from our current perspective.

$\S$ These were women without a malignant or benign ovarian condition. Historically, the terms 'prophylactic', 'elective' or 'incidental' oophorectomy were used; however, we avoided these terms.

${ }^{* *}$ Unable to estimate using conditional logistic regression models since the two cases with physical neglect were matched to controls who also had physical neglect (ie, there were no discordant matched pairs where the case had physical neglect but the matched control did not).

Using a logistic regression model that ignored the matching, the OR was 0.23 (95\% $\mathrm{Cl} 0.05$ to $1.11 ; \mathrm{p}=0.07$ ).

ACE, Adverse Childhood Experiences; OR, odds ratio; Cl, confidence interval. 
Table 5 Case-control analyses for adverse childhood experience score adjusted for possible confounder or mediation variables

\begin{tabular}{|c|c|c|c|c|}
\hline \multirow[b]{2}{*}{ Adjusting variable* } & \multicolumn{2}{|l|}{ Adjusting variable } & \multicolumn{2}{|l|}{$\begin{array}{l}\text { ACE score } \geq 1 \\
\text { (vs ACE score of } 0 \text { ) }\end{array}$} \\
\hline & OR $(95 \% \mathrm{Cl})$ & p Value & OR $(95 \% \mathrm{Cl})$ & p Value \\
\hline Univariable model & - & - & 3.23 (1.73 to 6.02$)$ & $<0.001$ \\
\hline \multicolumn{5}{|l|}{ Bivariable models } \\
\hline$>12$ years of education ( $v s \leq 12$ years) & 1.08 (0.64 to 1.83$)$ & 0.78 & 3.24 (1.74 to 6.04$)$ & $<0.001$ \\
\hline \multicolumn{5}{|l|}{ Marital status at index } \\
\hline Ever married (vs never married) & $1.08(0.47$ to 2.47$)$ & 0.85 & 3.21 (1.72 to 6.00$)$ & $<0.001$ \\
\hline Married at index (vs single, divorced or widowed) & $0.88(0.51$ to 1.51$)$ & 0.64 & 3.21 (1.72 to 5.99$)$ & $<0.001$ \\
\hline Any pregnancy before age 18 (vs none) & $1.46(0.54$ to 3.98$)$ & 0.45 & 3.24 (1.74 to 6.04$)$ & $<0.001$ \\
\hline Any births before index (vs none) & 0.66 (0.33 to 1.33$)$ & 0.24 & 3.39 (1.80 to 6.38$)$ & $<0.001$ \\
\hline \multicolumn{5}{|l|}{ Smoking status at index } \\
\hline Current or former smoker (vs never smoker) & 0.57 (0.32 to 1.01$)$ & 0.05 & 3.68 (1.91 to 7.08$)$ & $<0.001$ \\
\hline $\begin{array}{l}\text { Current smoker (vs never smoker or former } \\
\text { smoker) }\end{array}$ & $0.68(0.37$ to 1.23$)$ & 0.20 & 3.30 (1.76 to 6.17$)$ & $<0.001$ \\
\hline $\begin{array}{l}\text { Any substance abuse (drug or alcohol) at index (vs } \\
\text { none) }\end{array}$ & 0.71 (0.37 to 1.36$)$ & 0.31 & 3.46 (1.82 to 6.57$)$ & $<0.001$ \\
\hline $\mathrm{BMI} \geq 30 \mathrm{~kg} / \mathrm{m}^{2}$ at index $\left(\mathrm{vs} \mathrm{BMl}<30 \mathrm{~kg} / \mathrm{m}^{2}\right)$ & 1.05 (0.64 to 1.73$)$ & 0.85 & 3.23 (1.74 to 6.03$)$ & $<0.001$ \\
\hline Any eating disorder before index (vs none) & 1.13 (0.55 to 2.33$)$ & 0.74 & 3.19 (1.71 to 5.97$)$ & $<0.001$ \\
\hline Any anxiety or depression before index (vs none) & $0.84(0.49$ to 1.46$)$ & 0.54 & 3.41 (1.78 to 6.52$)$ & $<0.001$ \\
\hline $\begin{array}{l}\text { Any suicide attempt or suicidal ideation before index } \\
\text { (vs none) }\end{array}$ & 2.28 (0.95 to 5.50$)$ & 0.07 & 2.97 (1.58 to 5.57$)$ & $<0.001$ \\
\hline Multivariable model $\dagger$ & - & - & 3.87 (1.91 to 7.83 ) & $<0.001$ \\
\hline
\end{tabular}

${ }^{*}$ The ORs, Cls, and $\mathrm{p}$ values were calculated using conditional logistic regression models (matched pairs) for bilateral oophorectomy status (cases vs controls) predicted by ACE score $\geq 1$ (vs ACE score of 0 ). Models were fit overall with no adjusting variable and adjusted for each characteristic separately (bivariable models).

†Multivariable conditional logistic regression model adjusted for education ( $>12$ years vs $\leq 12$ years), marital status at index (ever married vs never married), any pregnancy before age 18 (vs none), any birth before index (vs none), smoking status at index (current or former smoker vs never smoker), any substance abuse before index (vs none), $\mathrm{BMI} \geq 30 \mathrm{~kg} / \mathrm{m}^{2}$ at index ( $\mathrm{vs} \mathrm{BMl}<30 \mathrm{~kg} / \mathrm{m}^{2}$ ), any eating disorder before index (vs none), any anxiety or depression before index (vs none) and any suicide attempt or suicidal ideation before index (vs none).

$\mathrm{ACE}$, Adverse Childhood Experiences; BMI, body mass index; OR, odds ratio; $\mathrm{Cl}$, confidence interval.

This study has several strengths. First, the recordslinkage system of the REP has been a unique resource to link events that occurred many decades apart (approximately 40 years in this study) and that were spread across paediatric, psychiatric, reproductive, preventive medicine, or gynaecological specialties. Second, we collected information about adverse experiences from the medical records, thus avoiding possible recall or reporting bias involved in interviews or mail surveys. ${ }^{15-18}$ Third, detailed information was available in the medical and psychiatric records of the REP about the adverse childhood experiences included in the ACE score and about abuse during adulthood. Many of these details would not be available from a single standardised interview conducted later in life. Finally, the participation of women in the study was high, because the rate of research authorisation in the REP is approximately $98 \% .^{18}$

The study has some limitations. First, we likely have underestimated the frequency of adverse experiences similar to what has been observed in other studies. ${ }^{19} 22$ Some women may not have reported adverse experiences at the time they occurred or at the time of their medical visits later in life even though they were asked specifically about such experiences. Indeed, a number of women only reported adverse childhood experiences many years after they had occurred, as part of a structured psychiatric evaluation and in the context of a depressive episode. Whether data are collected through an interview, a mail survey, or through medical record abstraction, the risk of underestimation is inherent to the sensitivity of the information. ${ }^{192}$ We are not aware of any study that compared information about adverse experiences abstracted from medical records with information self-reported via the ACE questionnaire.

Second, consistent with the original use of the ACE score, each one of the 10 items was given the same weight when we used cut-offs. ${ }^{19-21}$ However, some adverse childhood experiences may have been more emotionally traumatic than others. Therefore, we also conducted analyses for each experience separately. Finally, the same experience may have had greater or lesser impact depending on other factors such as the entire family 
environment (eg, presence of grandparents or other surrogate caring figures).

Third, because the data were collected historically via medical records abstraction, some adverse experiences, such as drug use by the parents, were not easy to obtain or to date. In addition, it was not possible to keep the medical record abstractor unaware of the oophorectomy status of the women, because a comprehensive review of the complete medical record was required to obtain detailed information. However, we developed specific guidelines to obtain and interpret the data, and we used the same guidelines for both cases and controls. In addition, our intra-rater reliability study, in which the abstractor was unaware of the results of her first abstraction, showed good agreement. Finally, the sample size of our study was limited for some of the stratified analyses. However, the sample was dictated by our decision to restrict the study to all of the complete pairs of women who had medical record information dating back to age 15 years or earlier.

\section{Comparison with other studies}

Our findings are consistent with a large body of literature showing associations between adverse childhood or adult experiences and several mental and somatic conditions. ${ }^{19252629}$ We briefly discuss only the studies that focused on gynaecological symptoms or conditions. An initial study showed an association of chronic pelvic pain with physical abuse, but not with sexual abuse in childhood. ${ }^{30}$ A second study showed an association of complaints of dysmenorrhea, menorrhagia, and sexual dysfunction with a history of sexual assault. ${ }^{31} \mathrm{~A}$ third study showed an increased risk of fibroids in women who experienced childhood abuse. ${ }^{32} 33$ A fourth study showed an increased occurrence of symptoms of pre-menstrual syndrome in women who underwent emotional and physical abuse. ${ }^{34}$ A recent study of women veterans showed an association of sexual assault with vaginal penetration at any time in life with hysterectomy (with or without concurrent bilateral oophorectomy). The association was partly mediated by an increased occurrence of gynaecological pain, abnormal uterine bleeding, and pelvic inflammatory disease. ${ }^{28}$ Another recent study showed an association of physical abuse with the risk of abdominal adhesions but not with the risk of endometriosis, ovarian cysts, or fibroids. ${ }^{35}$ Finally, a study showed an association between recent abuse and the severity of menopausal symptoms. $^{27}$

\section{Possible explanations of our findings}

Our findings could be the result of a confounding variable such as socioeconomic status which could independently increase the risk of adverse childhood or adult experiences and predispose women to hysterectomy with concurrent bilateral oophorectomy later in life. However, our analyses adjusted for educational level did not change the results. In addition, analyses adjusted for other indirect markers of socioeconomic status, such as cigarette smoking and substance abuse, did not change the results.
If the results are not due to chance or confounding and are not mediated through the several psychosocial or medical variables that we explored, they may suggest a causal link between the adverse childhood or adult experiences and gynaecological symptoms prompting a bilateral oophorectomy. The underlying mechanisms could be partly biological and partly emotional or psychodynamic.

A number of biological mechanisms may explain the link between adverse childhood or adult experiences and gynaecological symptoms. Experiments in mammals have shown an association between early abuse and poor development and poor adaptation that may be mediated by epigenetic modifications (primarily DNA methylation or histone modifications) ${ }^{36}$ For example, adverse experiences in early life may impact the hypothalamic-pituitary-adrenal axis (HPA) and its life-long response to stress. ${ }^{37}$ A review of several animal studies showed that stress may affect both the HPA and the hypothalamic-pituitary-ovarian (HPO) axes and may cause reduced activity of the ovaries and increased activity of the adrenal glands. These changes may result in increased production of progesterone, a hormone linked to symptomatic uterine fibroids. ${ }^{33}$ In women, uterine fibroids may cause chronic pelvic pain and excessive bleeding that may prompt the women to seek gynaecological care. In summary, adverse childhood or adult experiences may cause epigenetic modifications increasing the response of the HPA and HPO axes to stress, thus increasing the risk of uterine fibroids. Other yet unknown biological mechanisms may explain the link between the adverse experiences and chronic pelvic pain due to adenomyosis or without any recognised origin. Indeed, chronic pelvic pain has been associated with adverse childhood experiences and with a history of bullying. ${ }^{35} 3839$

In addition, psychodynamic mechanisms may have caused these women to experience gynaecological symptoms as particularly bothersome, potentially leading to more dramatic treatment considerations, such as invasive surgery, even when no underlying pathology had been identified. Indeed, in our study, the association with previous adverse experiences was stronger in the 63 women (49.2\%) who did not have a specified ovarian indication for the oophorectomy. A total of 26 women $(20.3 \%)$, in addition to having no ovarian indication, also had no recognised uterine condition. For these women, idiopathic chronic pelvic pain, abnormal uterine bleeding, or both were the only indication for the extensive surgery. Some of these women underwent repeated visits with a variety of medical providers in which they reported multiple symptoms and complaints, and often asked for the surgery as a "definitive solution". Few women linked the present gynaecological symptoms with traumatic experiences dating back to childhood or earlier adulthood, possibly because these traumatic events were inaccessible to their memory. Conceivably, this inability to retrieve and process their past experiences led some women to believe that their distress could be alleviated by removing their reproductive organs. 


\section{Implications for clinicians}

The lack of awareness of a past emotional trauma that strongly influences the current experiences is described as disavowal in the psychoanalytic literature and as experiential avoidance in the cognitive behavioural therapy literature. ${ }^{40-43}$ For many women, disavowal may have been a key mechanism leading to a request for surgery, even when gynaecological symptoms were unexplained or considered to be minor by the medical providers. By accepting the woman's request for surgery in the absence of a pathological indication, the physician may miss an important opportunity to help that woman understand the emotional and mental nature of her current symptoms. In addition, the oophorectomy may pose major harm to the woman due to the increased risk of premature morbidity and mortality. ${ }^{1-7}$

\section{CONCLUSIONS}

Women who suffered adverse experiences as a child or abuse during adulthood are at increased risk of undergoing bilateral oophorectomy before menopause, almost always in conjunction with a hysterectomy. The association does not appear to be mediated by a number of psychosocial or medical variables that we investigated. Therefore, we suggest that the association may be explained by a combination of biological, emotional, and psychodynamic mechanisms. We hope that this study will raise awareness among both women and gynaecological providers of the importance of considering childhood experiences and adult abuse and of discouraging oophorectomy in the absence of ovarian cancer or of a markedly increased risk of cancer (eg, carriers of high-risk genetic variants).

\section{Author affiliations}

${ }^{1}$ Division of Epidemiology, Department of Health Sciences Research, Mayo Clinic, Rochester, Minnesota, USA

${ }^{2}$ Division of Biomedical Statistics and Informatics, Department of Health Sciences Research, Mayo Clinic, Rochester, Minnesota, USA

${ }^{3}$ Women's Health Research Center, Mayo Clinic, Rochester, Minnesota, USA

${ }^{4}$ Division of General Internal Medicine, Women's Health Clinic, Mayo Clinic, Rochester, Minnesota, USA

${ }^{5}$ Department of Surgery, Mayo Clinic, Rochester, Minnesota, USA

${ }^{6}$ Division of Reproductive Endocrinology and Infertility, Department of Obstetrics and Gynecology, Mayo Clinic, Rochester, Minnesota, USA

${ }^{7}$ Department of Neurology, Mayo Clinic, Rochester, Minnesota, USA

Acknowledgements We thank Ms Robin Adams for her assistance in typing and formatting the manuscript.

Contributors LGR, CYS, BRG and WAR were involved in the conception and design of the study. LGR collected the data via medical record abstraction. LGR, CYS, BRG and WAR participated in data analysis. All authors (LGR, CYS, BRG, SSF, LTS, EAS and WAR) contributed to interpretation of the data and critical revision of the manuscript. All authors (LGR, CYS, BRG, SSF, LTS, EAS and WAR) also approved the final version to be published.

Funding This study used the resources of the Rochester Epidemiology Project, which is supported by the National Institute on Aging of the National Institutes of Health (NIH) under Award Number R01 AG034676. This study was also supported by funds from the Mayo Clinic Research Committee (to WAR). WAR was partly supported by the NIH grants P50 AG044170, U01 AG006786 and P01 AG004875.

Competing interests None declared.
Patient consent Informed consent was waived; however, we did not include data for any person who had not given permission for their medical records to be used for research (Minnesota Research Authorization).

Ethics approval This study was approved by the Mayo Clinic and Olmsted Medical Center Institutional Review Boards.

Provenance and peer review Not commissioned; externally peer reviewed.

Data sharing statement № additional data are available.

Open Access This is an Open Access article distributed in accordance with the Creative Commons Attribution Non Commercial (CC BY-NC 4.0) license, which permits others to distribute, remix, adapt, build upon this work non-commercially, and license their derivative works on different terms, provided the original work is properly cited and the use is non-commercial. See: http://creativecommons.org/ licenses/by-nc/4.0/

(C) Article author(s) (or their employer(s) unless otherwise stated in the text of the article) 2017. All rights reserved. No commercial use is permitted unless otherwise expressly granted.

\section{REFERENCES}

1. Rocca WA, Grossardt BR, de Andrade M, et al. Survival patterns after oophorectomy in premenopausal women: a population-based cohort study. Lancet Oncol 2006;7:821-8.

2. Rocca WA, Bower JH, Maraganore DM, et al. Increased risk of cognitive impairment or dementia in women who underwent oophorectomy before menopause. Neurology 2007;69:1074-83.

3. Rivera CM, Grossardt BR, Rhodes DJ, et al. Increased cardiovascular mortality after early bilateral oophorectomy. Menopause 2009;16:15-23.

4. Rocca WA, Gazzuola-Rocca L, Smith CY, et al. Accelerated accumulation of multimorbidity after bilateral oophorectomy: a population-based cohort study. Mayo Clin Proc 2016;91:1577-89.

5. Parker WH, Broder MS, Chang E, et al. Ovarian conservation at the time of hysterectomy and long-term health outcomes in the Nurses' Health Study. Obstet Gynecol 2009;113:1027-37.

6. Parker WH, Feskanich D, Broder MS, et al. Long-term mortality associated with oophorectomy compared with ovarian conservation in the Nurses' Health Study. Obstet Gynecol 2013;121:709-16.

7. Gierach GL, Pfeiffer RM, Patel DA, et al. Long-term overall and disease-specific mortality associated with benign gynecologic surgery performed at different ages. Menopause 2014;21:592-601.

8. Berek JS, Chalas E, Edelson M, et al. Prophylactic and risk-reducing bilateral salpingo-oophorectomy: recommendations based on risk of ovarian cancer. Obstet Gynecol 2010;116:733-43.

9. Jacoby VL, Grady D, Wactawski-Wende J, et al. Oophorectomy vs ovarian conservation with hysterectomy: cardiovascular disease, hip fracture, and cancer in the Women's Health Initiative Observational Study. Arch Intern Med 2011;171:760-8.

10. Vitonis AF, Titus-Ernstoff L, Cramer DW. Assessing ovarian cancer risk when considering elective oophorectomy at the time of hysterectomy. Obstet Gynecol 2011;117:1042-50.

11. Plusquin $\mathrm{C}$, Fastrez $\mathrm{M}$, Vandromme J, et al. Factors affecting gynaecologists' decision to perform prophylactic oophorectomy concomitantly with hysterectomy: a Belgian survey. Maturitas 2011;70:391-4.

12. Evans EC, Matteson KA, Orejuela FJ, et al. Salpingo-oophorectomy at the time of benign hysterectomy: a systematic review. Obstet Gynecol 2016;128:476-85.

13. Parker WH, Broder MS, Berek JS, et al. Salpingo-oophorectomy at the time of benign hysterectomy: a systematic review. Obstet Gynecol 2017;129:202.

14. Rocca WA, Faubion SS, Stewart EA, et al. Salpingo-oophorectomy at the time of benign hysterectomy: a systematic review. Obstet Gynecol 2017;129:202-3.

15. St Sauver JL, Grossardt BR, Yawn BP, et al. Use of a medical records linkage system to enumerate a dynamic population over time: the Rochester Epidemiology Project. Am J Epidemiol 2011;173:1059-68.

16. St Sauver JL, Grossardt BR, Leibson CL, et al. Generalizability of epidemiological findings and public health decisions: an illustration from the Rochester Epidemiology Project. Mayo Clin Proc 2012;87:151-60.

17. Rocca WA, Yawn BP, St Sauver JL, et al. History of the Rochester Epidemiology Project: half a century of medical records linkage in a US population. Mayo Clin Proc 2012;87:1202-13.

18. St Sauver JL, Grossardt BR, Yawn BP, et al. Data resource profile: the Rochester Epidemiology Project (REP) medical records-linkage system. Int J Epidemiol 2012;41:1614-24. 
19. Felitti VJ, Anda RF, Nordenberg D, et al. Relationship of childhood abuse and household dysfunction to many of the leading causes of death in adults. The Adverse Childhood Experiences (ACE) study. Am J Prev Med 1998;14:245-58.

20. Dong M, Anda RF, Felitti VJ, et al. The interrelatedness of multiple forms of childhood abuse, neglect, and household dysfunction. Child Abuse Negl 2004;28:771-84.

21. Dube SR, Anda RF, Felitti VJ, et al. Growing up with parental alcohol abuse: exposure to childhood abuse, neglect, and household dysfunction. Child Abuse Negl 2001;25:1627-40.

22. Hardt J, Rutter M. Validity of adult retrospective reports of adverse childhood experiences: review of the evidence. J Child Psychol Psychiatry 2004;45:260-73.

23. Dube SR, Williamson DF, Thompson T, et al. Assessing the reliability of retrospective reports of adverse childhood experiences among adult $\mathrm{HMO}$ members attending a primary care clinic. Child Abuse Negl 2004;28:729-37.

24. Kazeem OT. A validation of the adverse childhood experiences scale in Nigeria. Res on Humanities Soc Sci 2015;5:18-23.

25. Felitti VJ, Anda RF. The relationship of adverse childhood experiences to adult medical disease, psychiatric disorders, and sexual behavior: implications for healthcare. In: Lanius $R$, Veermetten E, eds. The Hidden Epidemic: the Impact of Early Life Trauma on Health and Disease. Cambridge: Cambridge University Press, 2010.

26. Nakazawa DJ. Childhood disrupted: how your biography becomes your biology, and how you can heal. New York: Atria Books, 2015.

27. Vegunta S, Kuhle C, Kling JM, et al. The association between recent abuse and menopausal symptom bother: results from the data registry on experiences of aging, menopause, and sexuality (DREAMS). Menopause 2016;23:494-8

28. Ryan GL, Mengeling MA, Summers KM, et al. Hysterectomy risk in premenopausal-aged military veterans: associations with sexual assault and gynecologic symptoms. Am J Obstet Gynecol 2016;214:352.e1-352.e13.

29. Puterman E, Gemmill A, Karasek D, et al. Lifespan adversity and later adulthood telomere length in the nationally representative US Health and Retirement Study. Proc Natl Acad Sci USA 2016;113:E6335-E6342.
30. Rapkin AJ, Kames LD, Darke LL, et al. History of physical and sexual abuse in women with chronic pelvic pain. Obstet Gynecol 1990;76:92-6.

31. Golding JM, Wilsnack SC, Learman LA. Prevalence of sexual assault history among women with common gynecologic symptoms. Am J Obstet Gynecol 1998;179:1013-9.

32. Boynton-Jarrett R, Rich-Edwards JW, Jun HJ, et al. Abuse in childhood and risk of uterine leiomyoma: the role of emotional support in biologic resilience. Epidemiology 2011;22:6-14.

33. Baird D, Wise LA. Childhood abuse and fibroids. Epidemiology 2011;22:15-17.

34. Bertone-Johnson ER, Whitcomb BW, Missmer SA, et al. Early life emotional, physical, and sexual abuse and the development of premenstrual syndrome: a longitudinal study. J Womens Health 2014;23:729-39.

35. Schliep KC, Mumford SL, Johnstone EB, et al. Sexual and physical abuse and gynecologic disorders. Hum Reprod 2016;31:1904-12.

36. Champagne FA. Epigenetic influence of social experiences across the lifespan. Dev Psychobiol 2010;52:299-311.

37. Gudsnuk K, Champagne FA. Epigenetic influence of stress and the social environment. Ilar J 2012;53:279-88.

38. Drevin J, Stern J, Annerbäck EM, et al. Adverse childhood experiences influence development of pain during pregnancy. Acta Obstet Gynecol Scand 2015:94:840-6.

39. Nault T, Gupta P, Ehlert M, et al. Does a history of bullying and abuse predict lower urinary tract symptoms, chronic pain, and sexual dysfunction? Int Urol Nephrol 2016:48:1783-8.

40. Martín Cabré LJ. The psychoanalytic conception of trauma in Ferenczi and the question of temporality. Am J Psychoanal 2008;68:43-9.

41. Garon J. From disavowal and murder to liberty. Am J Psychoanal 2012;72:33-45.

42. Tarantelli CB. The fear of turning into dust: notes on a group for sexually abused women. Am J Psychoanal 2012;72:52-63.

43. Hayes SC, Strosahl KD, Wilson KG. Acceptance and commitment therapy: the process and practice of mindful change. 2nd ed. New York / London: Guilford Press, 2012. 